\title{
Analyzing RCM Indicators in Continuous Production Lines A Case Study
}

\author{
Ehsan Pourjavad \\ Department of Industrial Engineering, Najafabad Branch, Islamic Azad University, Isfahan, Iran \\ Postal Code: 81966-75954, \#11, Q Block, Hezar Dastgah Residential Complex, 22 Bahman St. \\ Malek Shahr St., Isfahan, Iran \\ Tel: 98-311-434-6762Ｅ-mail: Ehsan.pourjavad@Gmail.com \\ Hadi Shirouyehzad (Corresponding author) \\ Department of Industrial Engineering, Najafabad Branch, Islamic Azad University, Isfahan, Iran \\ Postal Code: 81399-66387, Navid Al., Omid St., Khanehesfahan St., Isfahan, Iran \\ Tel: 98-331-229-1111Ｅ-mail: Hadi.shirouyehzad@gmail.com
}

Arash Shahin

Department of Management, University of Isfahan, Isfahan, Iran

1.242, Saeb Avenue, 81848-13713, Isfahan, Iran

Tel: 98-311-793-2040 E-mail: arashshahin@hotmail.com

Received: June 6, 2011 Accepted: June 15, $2011 \quad$ doi:10.5539/ibr.v4n4p115

\begin{abstract}
Along with the increasing expansion of technology and an increase in the competition between organizations, industries and organizations employ different strategies and policies to increase productivity and decrease organization costs. Maintenance is one of these policies which production industries with continuous arrangements use it to increase production, decrease costs and also stay in the circle of global competition. Maintenance systems have improved a lot in recent years. Reliability Centered Maintenance has been one of the latest technologies in maintenance to which the world is turning. This technology has different indicators and all of the industries use them to compare similar units or periods, and also they use the results of these indicators for taking maintenance decisions. We are going to study the dependency amount of two important scales called mean time to repair and mean time between failures with the amount of production in continuous line of production. In fact we want to survey the accuracy of available results of these indicators and applicability of their results. In this paper, we analyzed mean time to repair and mean time between failure indicators in Chadormalu industry-mining factory for four parallel lines of production during the years of 2008, 2009 and 2010 and specified the amount of their dependence with the amount of production and therefore it became clear that these indicators do not have dependency with the amount of production.
\end{abstract}

Keywords: Reliability Centered Maintenance (RCM), Mean Time Between Failure (MTBF), Mean Time To Repair (MTTR), Production, Correlation Analysis

\section{Introduction}

Nowadays along with the rapid development of industries in the world and organizations attempt for the continuity of production and also the increase of influence in the market, the decrease of the production cost and the attempt to set up the process of production, have turned to the most important challenges of production organizations. To reach to this goal continuity of production and also decrease of operation costs are set on the high agenda of production managers. (Swanson, 1997) Maintenance is generally identified as a single largest controllable cost and status quo represents a challenge for leading managements to reevaluate their maintenance strategies, decision making work attempts to understand different maintenance policies making for better maintenance of asset. (Rostamian, 2010)

A well-implemented integrated asset management and maintenance system can impact every section of an organization, increasing asset uptimes, reducing maintenance costs, increasing benefits, and enhancing the reputation of the business with its customers. When reliable information and effective decision-support tools are 
integrated under an asset management umbrella, the costs for maintenance, repair and renewal are substantially reduced. (Rostamian, 2010)

In pursuit of continuous improvement, two complementary methodologies that reflect various focuses are available (uptime) of physical assets, these methodologies are: (Andrew et al. 2006)

Total productive maintenance (TPM) - a people-centered methodology.

Reliability-centered maintenance (RCM) - an asset centered methodology.

Various articles have been written to survey influence maintenance on production rates that among them we can mention: Swanson (1997), in the article "An empirical study of the relationship between production technology and maintenance management" reports the results of a study of the relationship between the characteristics of production technology and maintenance practices. Based on the responses from a survey of plant managers and maintenance managers, the analysis shows a strong relationship between technical complexity and maintenance practices that increase the technical expertise of the maintenance workforce.

Alsyouf (2007), in the article "The role of maintenance in improving companies' productivity and profitability" illustrates how an effective maintenance policy could influence the productivity and profitability of a manufacturing process. Savsar (2006), in the article "Effects of maintenance policies on the productivity of flexible manufacturing cells" discusses a procedure that combines simulation and analytical models to analyze the effects of corrective, preventive, and opportunistic maintenance policies on productivity of a flexible manufacturing cell. Lin et al. (2011), in the article "The impact of inspection errors, imperfect maintenance and minimal repairs on an imperfect production system" develops an integrated model of production lot-sizing, maintenance and quality for considering the possibilities of inspection errors, preventive maintenance (PM) errors and minimal repairs for an imperfect production system with increasing hazard rates. They investigate the effects of inspection errors and PM errors on the minimum total cost of the optimal inspection interval, inspection frequency and production quantity.

Martorell et al. (1994), in the article "The use of maintenance indicators to evaluate the effects of maintenance programs on NPP performance and safety" presents the foundation of a methodology for a maintenance evaluation program based on maintenance indicators and how it is applied to monitoring the effectiveness of the maintenance at the Cofrentes NPP. Eti et al. (2006), in the article "Impact of corporate culture on plant maintenance in the Nigerian electric-power industry" influence maintenance surveyed in Nigerian industry. This paper advocates that maintenance should be managed better, in each organization, so as to cultivate a sense of ownership in the operators. Also autonomous maintenance teams, consisting of operators, engineers and managers, should be set up with the aims of improving personnel competence and equipment performance. Gupta et al. (2001), in article "The relationship between preventive maintenance and manufacturing system performance" relationship between maintenance and production surveyed. Oyebisi and Agboola (2003), in article "The impact of the environment on the growth of the Nigerian IT industry" examines the impact of the environment on the growth of the IT industry in Nigeria.

The basic aim of this paper is analyzing RCM indicators in Continuous Production Lines. RCM system has different indicators and in this paper we use MTTR, MTBF which are the most important and applicatory scales in this system. Many industries use these indicators for comparison and performance analysis of similar units or periods. To this point, we try in this article to state dependence of RCM indicators with amount of production. We are going to calculate the amount of change in the production with change of MTTR and MTBF indicators. To do this we utilize the analysis of correlation between the indicators of RCM and the amount of production. We also use the Pearson's correlation because we are measuring the correlation between two quantitative variables. For describing the problem better, in this article we survey correlation between RCM indicators and amount of production in Chadormalu factory.

The remainder of this paper is organized as follow: In Section 2 reliability centered maintenance method is reviewed. RCM indicators describe in section 3. Methodology and case study for survey correlation between RCM indicators and production are introduced in Section 4. Discussion and conclusions is presented in Section 5.

\section{Reliability-Centered Maintenance}

Correct maintenance planning is a complicated task. There are many causes of machine failure, and their properties are different. Some are depending on the age of machines, and some are purely stochastic. Monitoring of machine operation is not necessarily effective. Often bad maintainability is only enhanced by early design changes. There are different types of maintenance, such as time-based maintenance and condition-based maintenance. It is complicated whether to adopt time-based maintenance or condition-based maintenance. Maintenance cost very much depends on needed maintenance resources and facilities. In order to achieve rational total life cycle management, it is strongly 
desired to understand a systematic planning method of maintenance operations. Reliability-Centered Maintenance $(\mathrm{RCM})$ is one of the well-established systematic methods for selecting applicable and suitable maintenance operation types (Kumar et al. 2000). In RCM, failure consequences and their preventive operations are systematically analysis, and possible maintenance planning is determined. (Kimura et al. 2002)

\subsection{RCM history}

The concepts behind RCM are not new, having their source in the airline industry back in the 1960s. After several years of experience, in 1978, the US Department of Defense issued the MSG-3 (ATA, 1978), an Airline/Manufacturers Maintenance Program Planning Document. That year, Nowlan and Heap wrote a comprehensive document on the relationships among Maintenance, Reliability and Safety, entitled Reliability Centered Maintenance (Nowlan and Heap, 1978), making the RCM methodology. RCM extend throughout industries, specially those needing safety and reliability, during the 1980s and the 1990s, being now expanded to several industry fields. (Carreteroa et al. 2003)

\subsection{RCM approach}

Formal definitions of RCM are as follows:

It is a process used to settle the maintenance requirements of any physical asset in its operating context. (Moubray, 1991)

A process used to determine what must be done to ensure that any physical asset continues to fulfill its intended functions in its present operating context. (Agrawal, 1997)

RCM is a method for improving and selecting maintenance design alternatives based on safety, operational and economic criteria, RCM employs a system perspective in its analysis of system functions, failures of functions, and prevention of these failures. (Jones, 1997)

RCM is a system consideration of system functions, the way functions can fail, and a priority based consideration of safety and economics that identifies applicable and effective PM tasks. (Rausand, 1998)

In a nutshell, the RCM methodology is completely delineated in four unique features.

Preserve functions

Identify failure modes that can defeat function

Priorities function needs (via failure modes)

Choose only applicable and effective tasks

RCM focuses on "system function" approach. Compound redundant systems have reliability directly engineered into their design. The reliability of the system can be decreased if maintenance tasks and frequencies are not its integral components. Over maintenance decrease the system reliability on account of maintenance induced failures. For highly reliable system the system reliability very often is reduced due to human intervention under the pretext of PM. Hence, RCM methodology has been successful in building up highly reliable systems.

RCM benefits include:

The evolvement of high quality maintenance plans in less time and at lower cost.

The attainability of maintenance history for each system is able to correlate this experience with specified parts and their failure modes and criticalities.

The assurance that all maintenance significance parts and their failure modes and critically are considered in the development of maintenance requirements.

The increased probability that the level and content of the maintenance requirement is optimally indicated.

The basis for routine, on-line information exchange among the engineering staff and management even in a widely dispersed organization. (Deshpande and Modak, 2002)

\subsection{RCM Methodology}

RCM methodology (Moubray, 1996) has three major goals. First one is to increase safety and reliability of systems by focusing on the most significant functions. RCM is concerned mainly with what we want the equipment to do, not what it actually does. Second is to prevent or to mitigate the consequences of failures, not to prevent the failures themselves. The consequences of a failure disagree depending on where and how items are installed and operated. Third one is to decrease maintenance costs by escaping or removing maintenance actions that are not strictly necessary. It is no longer assumed that all failures can be prevented by PM, or that even if they could be prevented, 
it would be desirable to do so. As RCM provides a ranking of maintenance tasks for a system, it can be used as a good technique for improving a PM program (Hall, 1992). A formal review of failure results focuses attention on maintenance tasks that are more effective, diverting energy away from those which have little or no impact (IEC, 1982). This helps to ensure that whatever is spent on maintenance, it is spent where it will be more essential to ensure that the inherent reliability of the equipments is improved.

\section{RCM Indicators}

Given the developments achieved in the maintenance system of RCM in recent years, there have been explained lots of indicators for that, such as Mean Time Between Downing Events (MTBDE) and Mean Time Between maintenance (MTBM) and Availability Equipment (AE) and MTBF and MTTR, etc and we take the most important and most applicatory indicators of this maintenance system into consideration in this article. A usual measure used to depict the reliability characteristics of a repairable system is mean time between failures (MTBF). In most repairable systems, preventive maintenance used to decrease system failure frequency and hence increase the MTBF. It is easy that MTBF is the mean time to a repair service or an age replacement. Reliability is quantified as MTBF (Mean Time Between Failures) for repairable product and MTTF (Mean Time To Failure) for non-repairable product. A correct understanding of MTBF is significance. MTTR means Basic measure of the maintainability of repairable items, it represents the average (mean) time needed to repair a failed component or device.

\subsection{MTBF Indicator}

Mean time between failures (MTBF) is the predicted elapsed time between inherent failures of a system during operation. MTBF can be computed as the arithmetic mean (average) time between failures of a system. The MTBF is typically part of a model that assumes the failed system is immediately repaired (zero elapsed time), as a part of a renewal process. This is in contrast to the mean time to failure (MTTF), which measures average time between failures with the modeling assumption that the failed system is not repaired.

The definition of MTBF depends on the explanation of what is considered a system failure. For complex, repairable systems, failures are considered to be those out of design conditions which place the system out of service and into a state for repair. Failures which happen, can be left or maintained in an unrepaired condition, and do not place the system out of service, are not considered failures under this definition. In addition, units that are taken down for routine scheduled maintenance or inventory control, are not considered within the explanation of failure.

For each observation, downtime is the immediate time it went down, which is after (i.e. greater than) the moment it went up, uptime. The difference (downtime minus uptime) is the amount of time it was operating between these two occurrences. MTBF value prediction is a significance element in the development of products. Reliability engineers/ design engineers often utilize Reliability Software to calculate products' MTBF according to different methods/standards (MIL-HDBK-217F, Telcordia SR332, Siemens Norm, FIDES, UTE 80-810 (RDF2000), etc.). However, these "prediction" methods are not intended to reflect fielded MTBF as is commonly believed. The goal of these tools is to focus design efforts on the weak links in the design. And MTBF computed with below formula: (Amari, 2006)

$\mathrm{N}$ : Number of failures

$$
M T B F=T / N
$$

\section{T: Total time in available}

MTBF is usually confused with a component's functional life, even though the two concepts are not directly related. For example a battery may have a useful life of four hours, and an MTBF of 100,000 hours. These figures show that in a population of 1,000,000 batteries, there will be approximately ten battery failures every hour during a single battery's four-hour life span. Another common misconception about the MTBF is that it specifies the time (on average) when the probability of failure equals the probability of not having a failure (i.e. an availability of $50 \%$ ). This is only true for certain symmetric distributions. In many cases, such as the (non-symmetric) exponential distribution, this is not the case. In particular, for an exponential failure distribution, the probability that an item will fail at or before the MTBF is approximately 0.63 (i.e. the availability at the MTBF is $37 \%$ ). For typical distributions with some variance, MTBF only represents a top-level aggregate statistic, and thus is not appropriate for predicting specific time to failure, the uncertainty arising from the variability in the time-to-failure distribution. (Amari, 2006)

\subsection{MTTR Indicator}

Mean time to repair is a basic measure of the maintainability of repairable items. It represents the average time required to repair a failed component or device. Declared mathematically, it is the total corrective maintenance time divided by the total number of corrective maintenance actions during a given period of time. It generally does not 
include lead time for parts not readily attainable or other Administrative or Logistic Down time (ALDT). And MTTR computed with below formula: (Rawlings, 1987)

$$
\operatorname{MTTR}=T / N
$$

$\mathrm{N}$ : Number of failures

$\mathrm{T}$ : Times of failures

\section{Case study and Finding}

To state the correlation between RCM indicators and the amount of production, we used the information from Chadormalu mining-industrial factory which produces iron concentration and is located 180 kilometers away from Yazd. Chadormalu factory has parallel production lines that each one works separately from others. It is necessary to mention that all of the calculations have been carried out by SPSS software.

In order to state the amount of correlation between RCM indicators and the amount of production, we calculated the indicators of MTBF and MTTR on a monthly basis for each line. To calculate the scales in question, we used stoppage sheets from each line which are procured by the control chamber. Initially we calculated the length of access time for each line, to do this we calculated the whole length of time for the line in a month then we deducted the total length of time for programmed stoppages and after wards we got the total number of unplanned stoppages from the stoppage sheets in question. And using the following formula, we calculated the MTBF for each line in the years of 2008, 2009 and 2010.The results of it are shown in table (1).

\section{$\mathrm{MTBF}=\mathrm{T} \div \mathrm{N}$}

To calculate MTTR, we calculated the total length of time for unplanned stoppages from the daily stoppage sheet and divided it by the number of unplanned stoppages; the results of it are shown in table (2). We also calculated the amount of production of each line from the daily production report on a monthly basis; the results of it are shown in table (3). Correlation is a measure of relationship between two mathematical variables or measured data values, which includes the Pearson correlation coefficient as a special case. When variables are quantitative for stating their correlation, we use the analysis of Pearson's correlation. As a result in this article we also used the Pearson's correlation because we are measuring the correlation between two quantitative variables. The amount of MTBF, MTTR and production for each line has been of quantitative variables. To carry out the analysis of correlation between indicators of MTBF and MTTR and the amount of production for production lines of Chadormalu mining-industry factory, we used SPSS software and the results of this analysis is shown in the following table.(4)

Regarding to the carried out analysis and taken results, we noticed that the amount of production has lots of correlation with the access time. But correlation of the amount of production in production lines of Chadormalu mining-industry factory with the indicators of MTBF and MTTR was low, which have various reasons. The factory of Chadormalu has two kinds of stoppages: planned stoppages and unplanned ones, reviewing the stoppages of production lines, we noticed that the total length of time for planned stoppages are a lot more than the total length of line for unplanned ones and as a result the unplanned stoppages do not have much effect on the amount of production. It is necessary to state that the production qualifications are similar for all lines in all months of the year.

Many of the unplanned stoppages in lines were for a few minutes and the lines got started immediately. For calculating MTBF indicator, the number of breaking downs are set at the outlet, so by increasing the number of breaking downs, this indicator decreases, whereas in this condition increasing the number of breaking downs in the lines do not lead to the decrease in access time. For example many of unplanned stoppages have been because of the pull of rope switch related to the belt conveyors. The line has gotten started immediately for the stoppages which have been because of the vibration or the temperature of mills machine engines, and these stoppages wouldn't last more than a few minutes. MTBF and MTTR indicators have also been calculated from unplanned stoppages; as a result the amount of production has little correlation with these indicators. Another reason is that the proportion of time length for unplanned stoppages to the length of access time has been very low.

Note1: The stoppages of Chadormalu production lines are divided into two parts: programmed stoppages including the repairs of PM and changing of liners and pile. And we deducted the total length of planned stoppages from available time to calculate the lines access time.

Note2: It is necessary to mention that according to the definition of Japan industry standard, a breaking down is when an object such as a production system, a machine or a piece stops working or stops doing a specific task. There are two impressions inferred from breaking down, one which causes the whole of a task to stop and the other which leads to the decrease of a task and in this article we mean the first kind which causes the whole task to stop.

\section{Discussion and Conclusions}

As it is obvious, the most important factor for increasing product and productivity in the organizations of 
manufacturing specially, factories of continuous production with gross manufacturing, is maintenance strategy. To this point, factories continuously pursue different maintenance strategy for increasing organization productivity. Each maintenance strategies have various indicators and the organizations calculate their performance with the result of these indicators. Reliability centered maintenance is one of the latest maintenance strategies that its usage increased nowadays between the most industries of the world. RCM has several indicators, that each of them calculates the maintenance performance from different aspects.

In this article, we surveyed two critical indicators of RCM strategy and calculated the correlation between quantities of product and these indicators in a case study. Mean time between failures is calculated from dividing the total time in available by the numbers of failures. The goal of production systems is increasing MTBF indicator and prospecting with increasing MTBF, the quantity of production increases too, because when this indicator increases, the distance between stoppages increase too. Always it's not the case and we can't trust to the results of MTBF in continuous production systems. For the better understanding of this problem, please attend to this example: suppose one production line has 700 hour in available and $\mathrm{N}$ ton production. This line in this month had 20 hour unplanned stoppages that cause from twenty stoppages of one hour, hence MTBF is 35 hour in this line. If this line have had 700 hour in available and 20 hour unplanned stoppages in another month, it should have had $\mathrm{N}$ ton production, because production qualification is similar for all months and production lines. If 20 hour stoppage in second status cause from three stoppages of 5, 6 and 9 hours, MTBF in this status is 233.3 hours. If comparison between two status was in the basis of MTBF indicators, it is expected that by a great increase in MTBF indicator, the quantity of production increased too, but this is not the case because in both months, the amount of time was similar. Mean time to repair is calculated by dividing times of unplanned stoppages by the number of unplanned stoppages, that the aim is decreasing this indicator. In the above example if we calculate MTTR for both two status, for the first status, MTTR is 1 hour and for the second status is 6.6 hour, and it was prospected that with increasing MTTR, quantity of production would decrease, but this will not happen.

The basic aim of this article is to survey RCM indicators better and to calculate the correlation between the quantity of production and MTBF and MTTR indicators in continuous production lines. Industries use the results of these indicators for comparison and analysis between similar periods or units. According to the results of these indicators, industries choose suitable strategies for improvement of the organization. Therefore, it is critical for the organizations to use correct and suitable indicators for comparison and analysis. Industries should survey indicators and specify suitable ones for comparison and analysis between similar periods and units before using them. For example: MTBM, MTTRs, number of failures, ratio of failures, percent of stoppage, percent of quality, availability, efficiency and OEE are the other indicators that industries can use for comparison and analysis. And industries should not limit themselves with one indicator for comparison and analysis, they should use multiple indicators. Multi criteria decision making is one of the best methods for comparison and analysis. Industries can use MCDM methods for comparison between similar units and periods in the basis of multiple indicators.

As it was said, maintenance is the most important factor for increasing the amount of production in continuous production and with the improvement of this system; we can see considerable results in the amount of production. For this purpose in this article, we reviewed the correlation amount of mean time between failure and mean time to repair indicators with the amount of production and as a result, the mentioned correlation was very low in this case study. But this is the result that was concluded from this sample study and it is possible that in other production systems, the amount of dependence between these indicators and the amount of production would be high. Hence, it is suggested to industries to use multiple indicators for performance measurement and comparison between similar units. Also for the next researches, it is recommended to survey correlation between other maintenance indicators and quantity of production and to present new methods for the evaluation of maintenance indicators.

\section{References}

Agrawal. VK, Gandhi. OP. (1997). Reliability-Centered Maintenance, Proceedings of SERC School on RAM, IIT Delhi, India.

Alsyouf, A. (2007). The role of maintenance in improving companies' productivity and profitability. International Journal of Production Economics. 105, 70-78. doi:10.1016/j.ijpe.2004.06.057, http://dx.doi.org/10.1016/j.ijpe.2004.06.057.

Amari, S.V. (2006). Bounds on MTBF of Systems Subjected to Periodic Maintenance. IEEE Transaction on Reliability. 55, $469-475$.

Andrew K.S. Jardine and albert H.C.Tsang. (2006). Maintenance, replacement, and reliability: theory and application, Published by CRC Press. 
ATA. (1978). $M S G-3$, revision 2. ATA of America.

Carreteroa, J. Pe 'reza, J. a-Carballeiraa, F.G. Caldero 'na, A. ndeza, A.F. Jose, D. Lozanob, A. Cardonab, L. Cotainac, N. Prete, P. (2003). Applying RCM in large scale systems: a case study with railway networks, Reliability Engineering and System Safety. 82. 257-273. doi:10.1016/S0951-8320(03)00167-4, http://dx.doi.org/10.1016/S0951-8320(03)00167-4.

Deshpande, V.S. Modak, J.P. (2002). Application of RCM to a medium scale industry, Reliability Engineering and System Safety. 77, 31-43. doi:10.1016/S0951-8320(02)00011-X, http://dx.doi.org/10.1016/S0951-8320(02)00011-X

Eti, M.C. Ogaji, S.O.T. and Probert. S.D. (2006). Impact of corporate culture on plant maintenance in the Nigerian electric-power industry. Applied Energy. 83, 299-310. doi:10.1016/j.apenergy.2005.03.002, http://dx.doi.org/10.1016/j.apenergy.2005.03.002.

Gupta, D. Günalay, Y. Srinivasan, M. (2001). The relationship between preventive maintenance and manufacturing system performance. European Journal of Operational Research. 132, 146-162. doi:10.1016/S0377-2217(00)00118-1, http://dx.doi.org/10.1016/S0377-2217(00)00118-1.

Hall R. (1992). Optimizing preventive maintenance using RCM. Maintenance, 7(4).

IEC. (1982). Dependability management. Application guide: maintainability. IEC; Part 3-10.

Jones, RB. (1997). Risk-based management. Mumbai, India, Jaico Publishing House.

Kimura, F. Hata, T. Kobayashi, N. (2002). Reliability-Centered Maintenance Planning based on Computer-Aided FMEA. The 35th CIRP-International Seminar on Manufacturing Systems, Seoul, Korea.

Kumar, U. Crocker, J. Knezevic, J. and El-Haram, M. (2000). Reliability, Maintenance and Logistic Support. Kluwer Academic Publishers.

Lin, Y.H. Chen, J.M. Chen, Y.C. (2011). The impact of inspection errors, imperfect maintenance and minimal repairs on an imperfect production system. Mathematical and Computer Modelling. 53, 1680-1691. doi:10.1016/j.mcm.2010.12.040, http://dx.doi.org/10.1016/j.mcm.2010.12.040

Martorell, S. Sanchez, A. Muñoz, A. Pitarch, J.L. Serradell, V. Roldan, J. (1994). The use of maintenance indicators to evaluate the effects of maintenance programs on NPP performance and safety. Reliability Engineering \& System Safety. 65(2), 85-94. doi:10.1016/S0951-8320(98)00088-X, http://dx.doi.org/10.1016/S0951-8320(98)00088-X .

Moubray, J. (1991). Reliability centered maintenance, Oxford: Butter worthy/Heinemann.

Moubray J. (1996). Maintenance management: a new paradigm. Maintenance, 11(1).

Nowlan FS, Heap HF. (1978). Reliability-centered maintenance. Technical report AD/A066-579. National Technical Information Service, US Department of Commerce, Springfield, Virginia.

Oyebisi, T.O. Agboola, A.A. (2003). The impact of the environment on the growth of the Nigerian IT industry. International Journal of Information Management. 23, 313-321. doi:10.1016/S0268-4012(03)00053-7, http://dx.doi.org/10.1016/S0268-4012(03)00053-7 .

Rausand, M. (1998). Reliability centered maintenance. Reliab Engng Sys Safety. 60, 121-32. doi:10.1016/S0951-8320(98)83005-6, http://dx.doi.org/10.1016/S0951-8320(98)83005-6 .

Rostamian, H. (2010). Optimizing Maintenance Strategies: Concept \& Techniques. The $6^{\text {th }}$ conference on maintenance, Tehran.

Rawlings, P.E. (1987). Maintenance element of probabilistic approach to project life cycle coasting, International journal of project management. 5, 149-154.

Savsar, M. (2006). Effects of maintenance policies on the productivity of flexible manufacturing cells. Omega. 34, 274-282. doi:10.1016/j.omega.2004.10.010, http://dx.doi.org/10.1016/j.omega.2004.10.010

Swanson, L. (1997). An empirical study of the relationship between production technology and maintenance management. International Journal of Production Economics. 53, 191-207. doi:10.1016/S0925-5273(97)00113-8, http://dx.doi.org/10.1016/S0925-5273(97)00113-8 . 
Table 1. Calculation of Mean Time Between Failure

\begin{tabular}{|c|c|c|c|c|c|c|c|c|c|c|c|c|}
\hline \multicolumn{13}{|c|}{ MTBF } \\
\hline \multicolumn{13}{|c|}{2008} \\
\hline LINE & January & February & March & April & May & June & July & August & September & October & November & December \\
\hline 1 & 106.33 & 48.56 & 44.50 & 55.59 & 90.75 & 78.69 & 138.35 & 55.07 & 86.84 & 77.20 & 50.05 & 113.48 \\
\hline 2 & 124.56 & 66.60 & 39.98 & 72.13 & 82.04 & 71.26 & 172.62 & 69.05 & 46.35 & 39.25 & 87.88 & 138.00 \\
\hline 3 & 67.05 & 103.89 & 43.86 & 72.05 & 55.24 & 57.31 & 98.76 & 124.83 & 101.32 & 77.45 & 114.13 & 142.05 \\
\hline 4 & 32.76 & 39.23 & 40.03 & 53.15 & 65.14 & 50.33 & 63.21 & 86.17 & 66.11 & 138.74 & 62.24 & 188.97 \\
\hline \multicolumn{13}{|c|}{2009} \\
\hline & January & February & March & April & May & June & July & August & September & October & November & December \\
\hline 1 & 92.50 & 54.36 & 71.83 & 120.04 & 82.17 & 283.60 & 116.66 & 88.04 & 72.81 & 232.72 & 116.31 & 59.23 \\
\hline 2 & 69.27 & 44.95 & 179.47 & 65.59 & 69.47 & 89.56 & 115.56 & 43.20 & 100.45 & 81.81 & 194.31 & 79.66 \\
\hline 3 & 72.47 & 78.61 & 71.71 & 76.21 & 61.00 & 59.65 & 119.29 & 106.15 & 176.04 & 217.28 & 67.92 & 27.40 \\
\hline 4 & 92.63 & 75.46 & 102.22 & 60.63 & 137.67 & 71.58 & 48.34 & 57.46 & 54.07 & 40.80 & 88.48 & 90.99 \\
\hline \multicolumn{13}{|c|}{2010} \\
\hline & January & February & March & April & May & June & July & August & September & October & November & December \\
\hline 1 & 92.79 & 103.95 & 165.36 & 144.76 & 49.22 & 66.21 & 46.13 & 100.44 & 83.58 & 116.60 & 69.36 & 123.72 \\
\hline 2 & 88.82 & 45.44 & 239.71 & 40.92 & 84.41 & 60.64 & 116.29 & 28.13 & 25.03 & 63.59 & 49.61 & 98.85 \\
\hline 3 & 59.76 & 80.86 & 70.96 & 55.69 & 60.18 & 68.72 & 57.47 & 140.64 & 46.71 & 54.87 & 138.58 & 103.16 \\
\hline 4 & 74.59 & 93.90 & 240.88 & 65.87 & 57.12 & 103.23 & 58.10 & 24.96 & 40.19 & 117.05 & 63.04 & 115.84 \\
\hline
\end{tabular}

Table 2. Calculation of Mean Time to Repair

\begin{tabular}{|c|c|c|c|c|c|c|c|c|c|c|c|c|c|}
\hline \multicolumn{10}{|c|}{ MTTR } \\
\hline \multicolumn{10}{|c|}{ | 008} \\
\hline LINE & January & February & March & April & May & June & July & August & September & October & November & December \\
\hline 1 & 0.73 & 2.33 & 2.48 & 2.19 & 0.65 & 0.58 & 0.47 & 1.29 & 1.16 & 1.23 & 0.96 & 0.22 \\
\hline 2 & 0.82 & 1.47 & 2.96 & 1.24 & 0.55 & 0.96 & 2.49 & 1.38 & 0.81 & 3.45 & 1.06 & 1.43 \\
\hline 3 & 1.42 & 0.75 & 2.25 & 0.95 & 1.19 & 1.15 & 0.80 & 0.89 & 0.82 & 1.41 & 1.03 & 0.45 \\
\hline 4 & 2.49 & 2.40 & 2.41 & 1.32 & 1.66 & 2.33 & 1.26 & 1.01 & 1.32 & 1.14 & 1.19 & 0.87 \\
\hline \multicolumn{10}{|c|}{2009} & & & \\
\hline \\
\hline 1
\end{tabular}


Table 3. Quantity of Production

\begin{tabular}{|c|c|c|c|c|c|c|c|c|c|c|c|c|}
\hline \multicolumn{13}{|c|}{ PRODUCTION } \\
\hline \multicolumn{13}{|c|}{2008} \\
\hline LINE & January & February & March & April & May & June & July & August & September & October & November & December \\
\hline 1 & 182672 & 197355 & 155589 & 205293 & 163054 & 186314 & 207697 & 158685 & 197171 & 205662 & 124411 & 158870 \\
\hline 2 & 177244 & 126973 & 188268 & 209847 & 145907 & 195957 & 201304 & 165807 & 192666 & 127353 & 183785 & 149110 \\
\hline 3 & 169253 & 208784 & 152006 & 211364 & 194123 & 141707 & 205725 & 188250 & 174953 & 209602 & 150358 & 158885 \\
\hline 4 & 156125 & 158472 & 188057 & 168591 & 212267 & 145896 & 189714 & 205654 & 169107 & 209044 & 147426 & 159253 \\
\hline \multicolumn{13}{|c|}{2009} \\
\hline & January & February & March & April & May & June & July & August & September & October & November & December \\
\hline 1 & 181301 & 175054 & 196417 & 194491 & 183346 & 157487 & 197063 & 187516 & 136013 & 184124 & 178716 & 154282 \\
\hline 2 & 170049 & 153634 & 194099 & 192893 & 127762 & 193585 & 192516 & 135772 & 192369 & 173065 & 148253 & 168778 \\
\hline 3 & 165574 & 167027 & 187488 & 137792 & 178391 & 187247 & 170347 & 170275 & 195752 & 180267 & 158957 & 153263 \\
\hline 4 & 175047 & 182328 & 193269 & 163479 & 187182 & 191307 & 157496 & 183440 & 194629 & 163028 & 157209 & 171211 \\
\hline \multicolumn{13}{|c|}{2010} \\
\hline & January & February & March & April & May & June & July & August & September & October & November & December \\
\hline 1 & 157568 & 188871 & 187124 & 194803 & 170087 & 183340 & 170233 & 185263 & 130586 & 193326 & 198662 & 176153 \\
\hline 2 & 153170 & 189915 & 200144 & 150283 & 186672 & 190582 & 187328 & 131621 & 189793 & 192893 & 199726 & 171671 \\
\hline 3 & 168046 & 184770 & 133215 & 198019 & 192297 & 180124 & 155444 & 183385 & 187376 & 146989 & 201274 & 181498 \\
\hline 4 & 121537 & 149882 & 204152 & 199623 & 196335 & 167319 & 193756 & 161125 & 152452 & 199409 & 202082 & 164769 \\
\hline
\end{tabular}

Table 4. Correlation between production and MTBF, MTTR

\begin{tabular}{|c|c|c|}
\hline LINE & $\begin{array}{c}\text { correlation between MTBF } \\
\text { and Production }\end{array}$ & $\begin{array}{c}\text { correlation between MTTR } \\
\text { and Production }\end{array}$ \\
\hline 1 & 0.116 & 0.19 \\
\hline 2 & 0.232 & -0.098 \\
\hline 3 & 0.232 & -0.226 \\
\hline 4 & 0.258 & -0.491 \\
\hline
\end{tabular}

\section{OPERATION}

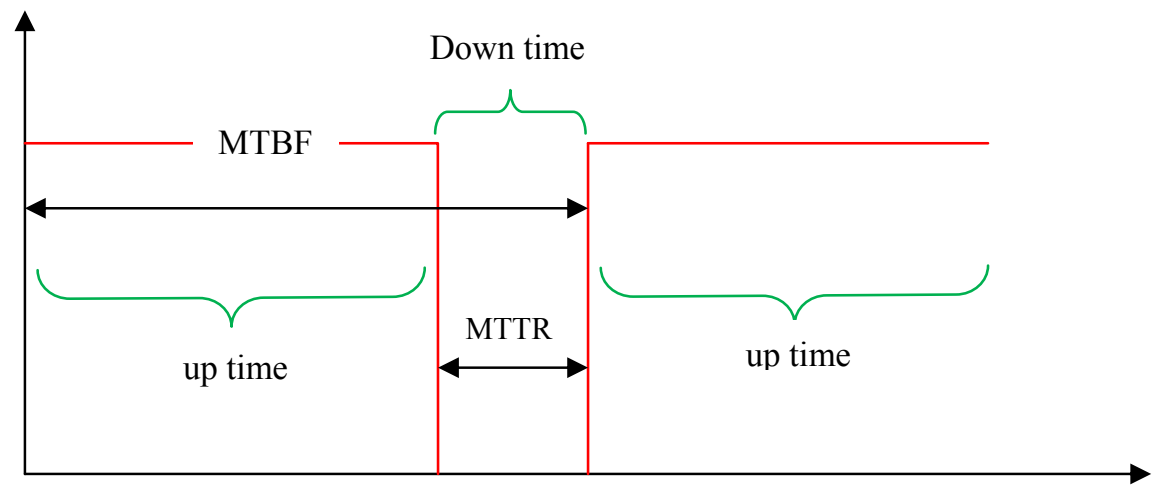

Figure 1. Mean Time Between Failure, Mean Time To Repair 